\title{
NOVES DADES ARQUEOLÒGIQUES SOBRE LES MURALLES MEDIEVALS DE TARRAGONA (S. XII-XIV)
}

\author{
Taller Escola d'Arqueologia (TED'A)
}

\section{INTRODUCCIÓ}

Des del 1987 fins al 1989 les intervencions arqueològiques realitzades pel TED'A a diversos punts del casc antic de Tarragona han aportat noves dades referents a l'evolució topogràfica de la ciutat en època medieval i, en concret, al traçat de la seva xarxa murària en el sector meridional del nucli urbà.

D'una banda, la intervenció realitzada en el núm. 20 del carrer dels Ferrers ha permès documentar una part del mur construït al segle XII entre les torres del Pretori i de l'antiga Audiència, com també la part inferior de la torre que flanquejava per occident el portal de n'Olivera. D'altra banda, els treballs portats a terme en la capçalera del circ han fet possible la recuperació d'una part del llenç meridional de la muralla del segle XIv, construïda al llarg del que avui és la Rambla Vella (Fig. 1, A i B).

Aquestes dues intervencions permeten estudiar diversos aspectes relacionats amb l'evolució del recinte emmurallat de la ciutat medieval amb les tècniques constructives emprades, i, al mateix temps, demostren la incidència decisiva de l'urbanisme de l'antiga ciutat romana en les successives transformacions del nucli urbà en època medieval.

\section{LES MURALLES DE TARRAGONA ENTRE ELS SEGLES XII I XIV SEGONS LA DOCUMENTACIÓ ESCRITA}

A partir de la documentació històrica i arqueològica disponible, no sembla que el domini musulmà de Tarragona signifiqués res més que una ocupació dispersa entre les ruïnes d'una gran ciutat antiga. Només un segle després de l'ocupació musulmana de Tarragona, la frontera era ja força al sud 


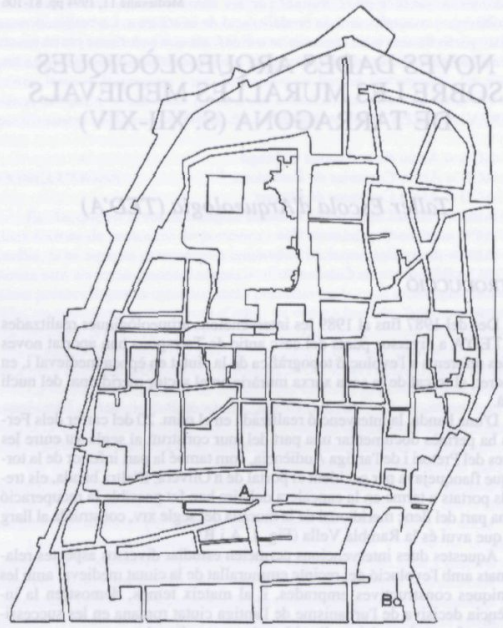

Fig. 1. Situació de les intervencions arqueològiques: nủm. 20 del carrer dels Ferrers (A) i núm. 3 de la Rambla Vella - capçalera del circ (B) (TED'A). 
de Barcelona. L'avanç cristià i la proximitat d'altres importants punts musulmans en la línea de l'Ebre impediren el manteniment d'una vida urbana d'acord amb el seu brillant passat. Ni la documentació històrica (Virgili, 1984) ni les restes arqueològiques tradicionalment atribuïdes a la Tarragona musulmana (Circ 1988, 20-21) no permeten demostrar amb claredat l'existencia d'una vida urbana digna de tal nom. Només, com la descriuria Yãgût en els segles XII i XII, es tractaria «d'un petit poble (balda), a al-Andalus, contigu a les dependències de Tortosa» (Virgili, 1984, 20, nota 92). El fragment de mirhab - que fins fa poc ha estat encastat, des de 1802, en un mur del claustre de la Catedral-, tradicionalment atribuit a la mesquita de la ciutat, era el principal argument historic a favor de l'existència d'un nucli urbà, juntament amb unes breus citacions textuals d'al-Rāzĩ o d'al-Himyarĩ que tan sols proven la riquesa agrícola de la comarca, únicament ocupada per establiments rurals (Recasens, 1975, 69-81; Virgili, 1984, 26). És probable, tanmateix, que aquest element arquitectònic, ricament decorat, sigui en realitat una part del botí transportat des del sud peninsular per les ràtzies cristianes. Alguns pocs fragments de ceràmica almohade procedents de les proximitats del Francolí, posterior ja a l'ocupació cristiana de la ciutat és tot allò que l'arqueologia urbana de Tarragona ha pogut fins ara aportar a aquesta quiestió (Serra, 1935, 75, làm. XLV, 11-14; TED'A 1987, 103-104, fig. 85).

El repoblament definitiu de Tarragona - després d'una sèrie d'intents iniciats ja al segle XI- es produeix durant la primera meitat del segle XII, com proven el document de donació de la ciutat per part del comte de Barcelona, Ramon Berenguer IV i el conegut testimoni d'Olderic Vitalis que descriu en aquest moment les romanalles de l'antiga urbs (Recasens, 1975, 44; Circ, 1988, 21). L'estat en què es trobava la ciutat és incert, però els escassos testimonis que ens han arribat coincideixen a descriure una ciutat en gran part abandonada però que encara mantenia en peu bona part dels seus edificis antics.

Els primers repobladors cristians es van situar en la part alta del turó tarragoní, encara envoltat per les muralles d'època romana i ocupada en el seu interior pels enormes edificis que en època altoimperial (s. I dC) conformaren l'anomenat Fòrum Provincial de Tàrraco, el centre religiós $\mathrm{i}$ administratiu de la província Hispania Citerior (Alföldy, 1978; TED'A, 1989). Els avantatges que oferia el lloc eren evidents, i la presència d'edificacions anteriors facilitava les tasques d'ocupació i de fortificació (Fig. 2).

El recinte murat que encerclava la ciutat dels primers repobladors cristians és encara força desconegut. L'escassa documentació històrica de què disposem ens apareix fragmentària i confusa. Els nombrosos problemes toponímics referents a les diferents parts de la muralla fan difícil la seva identificació i les restes arquitectòniques han estat profundament transformades en èpoques posteriors. Tot $i$ això, sabem que l'anomenat Mur Vell, esmentat en els textos del final del segle xrv en contraposició al Mur Nou ( $\%$ Mu- 


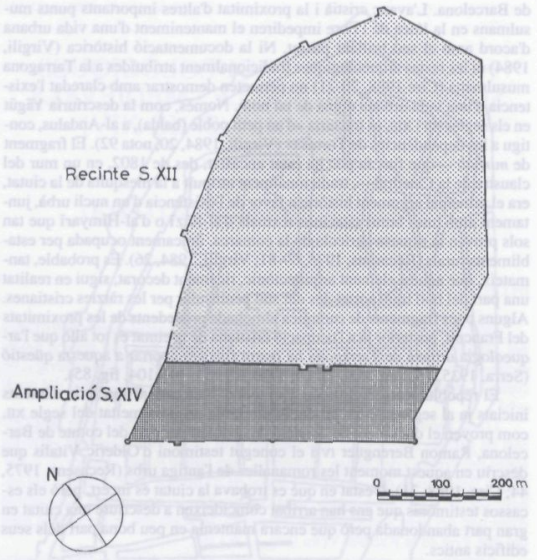

Fig. 2. El recinte ocupat en el segle XII, i l'ampliació del segle xIV —amb la incorporació del raval del Corral a la ciutat- (TED'A).

ralletas), comprenia el traçat de l'antiga muralla romana adaptada a l'abrupta topografia de la part superior del turó tarragoní vers el nord. l'est i l'oest. No obstant això, cap al sud, els desnivells havien estat corregits per les construccions en terrassa de la ciutat romana, que s'estenia des de dalt del turó fins a la badia portuària. En el segle XII, l'escassa grandària del nou nucli feudal va fer que només s'ocupés la part superior de la muntanya; les rünes de l'antic circ quedaren ja fora de la ciutat. Les muralles romanes van ser convenientment adobades; s'hi van mantenir les estructures originals i se n'hi van afegir algunes de noves, com les portes de la Presó Vella i la del Temple, i els portals de predicadors i el de Sant Antoni (Palma, 1956, 37-38). 
A la vessant sud, en direcció al port, es va construir un nou llenç de muralla aprofitant el mur de contenció de la gran plaça del Fòrum provincial romà, recolzat en els seus extrems en les torres conegudes com de l'Audiència i del Castell del Rei. Aquest mur limitava amb les estructures restants de l'antic circ - convertides ara en un espai extraurbà - el raval anomenat kel Corral» (sobre el «mur del Corral», que no s'ha de confondre amb el «mur nou» del segle XIv, vegeu Actes, 1983, 154-155).

De la distribució interna del nou nucli s'ha ocupat recentment Riu (1987), qui ha remarcat la separació existent entre les estructures arquitectòniques de domini eclesiàstic que ocupaven la part superior del turó i organitzades entorn de la catedral, començada a construir pels volts de 1170 (Villanueva, pp. 105-107: v. document de 1171 «incipiendum opus ecclesiae»; Recasens, 1975, 82) i les residències fortificades de les poderoses families feudals que havien dirigit la repoblació. Els documents de l'època ens recorden el conflicte de poders que es plantejà durant aquesta primera fase de l'ocupació cristiana entre l'autoritat eclesiàstica, la comtal i la família del princeps Robert Bordet (o d'Aguiló), conflicte que condú el 1173 a la concòrdia ad perennem entre el comte de Barcelona. Alfons I, i l'arquebisbe Guillem de Torroja, i a la separació de l'administració urbana de la familia de Robert (Blanch, 1951, 106-108). Sembla que començà (efectivament) la construcció de la catedral després de l'acord de 1173, signat pocs mesos abans de la mort de l'arquebisbe Guillem (9/3/1174).

La nova muralla que delimitava la part sud de la ciutat recolzava en el seu extem oriental en el castell que s'havia bastit aprofitant les restes d'una antiga torre romana. En l'extem oposat, una altra torre - simètrica - possiblement fou ocupada també pel castell pertanyent al bisbe de Vic, de situació encara imprecisa. En la seva part central, aproximadament en l'eix de al'acròpolis eclesiàstica» i de la nova catedral, se situa un dels accessos a la ciutat, flanquejat per torres, anomenat en els textos la porta Olivarie (1276) o de n'Olivera.

Entorn dels nuclis de poder eclesiàstic i feudal es va construir la nova ciutat, que s'adaptà a les gegantines fonamentacions d'època altoimperial que feien inútil, per als mitjans de l'època, qualsevol intent de replantejament urbanistic. Únicament els revestiments i les plaques de marbre, juntament amb els frisos i les cornises del mateix material o la nombrosa estatuària dispersa, lentament desmuntats per a llur conversió en calç, i els murs de carreus, desmuntats amb palanques per a la seva reutilització, despertaven l'interès dels nous constructors.

A partir d'aquest primer nucli, durant els segles XIII $\mathrm{i}$ XIv, la població es va anar estenent fora de la muralla, sobretot al voltant del port $\mathrm{i}$ al costat de la muralla sud de la ciutat, en el sector de l'antic circ, denominat en els textos «el Corral». L'hàbitat dispers del Corral degué produir-se des de bon començament, ja que la conservació d'una part de les estructures del circ per- 
metia un establiment ràpid $i$ molt proper a la ciutat emmurallada. N'és una prova l'existència d'una esglèsia, la de Sant Salvador (eclesiam sancti Salvatoris in suburbio Terrachonensis; doc. del 24/10/1128, publicat per Valls, 1926). Posteriorment, d'altres notícies continuen referint-se a l'establiment definitiu de la població en aquest sector (Circ, 1988). Aquest fet provocà que durant la guerra que va enfrontar el rei Pere III amb l'homònim rei de Castella, aquest sector s'incorporés definitivament al recinte urbà mitjançant la construccí d'una nova muralla: «el mur del carrer losat» (Actes, 1984, 13) 0 emur avayl del Corral» 0 , adhuc, «mur del Corral» (amb perill de confusí amb el «Mur Vell»).

La conservació d'alguns dels llibres d'actes municipals d'aquest moment ens permet de recollir tot un seguit de notícies referents als treballs de fortificació de la ciutat durant aquest període $\mathrm{i}$ als problemes econòmics que originava el seu pagament. La creixent inestabilitat política a partir de la segona meitat del segle XIV va obligar la ciutat a tenir una preocupació més gran per la seva defensa. Així, en les actes municipals de 1359, ja són nombroses les resolucions del Consell orientades al cobrament dels tributs destinats a la reparació de les muralles del primer cercle murat (Actes 1983, 58, 63, 77 i 141). $\mathrm{Al}$ final d'aquest mateix any, el Consell determinà que els tributs recaptats més avall del portal de n'Olivera fossin destinats «in operibus muri del Corraln referint-se a la cortina de muralla situada entre les torres de l'Audiència i del Pretori. Al mateix temps, els treballs de fortificació es van començar a estendre més enllà del recinte originari, concretament en el Corral ( cin consimilibus partibus del Corral extra murum civitatis») $\mathrm{i}$ als voltants del port. Per aquest motiu, el Consell va designar un escrivà $\mathrm{i}$ un administrador per a l'obra que s'havia de fer adel Corral a avall» (Actes, 1983, 155).

En els anys següents, l'arquebisbe Clasquerí, com a senyor de la ciutat, ordenà un seguit de mesures per al manteniment de la muralla. El 1360 va fer contractar uns pedrers d'Alforja per reparar-la (Morera, 1899, 469) i l'any següent ordenava l'enderroc d'una latrina que es trobava adossada a la muralla (Vertamon, $1683,38 \& 70$ ). Dos anys més tard insistí en la seva reparació (Vertamon, 1683, 39 \$73) i el 1364 comissionà Arcat de Talarn com a supervisor de les obres de la muralla i de l'enderrroc de totes aquelles cases que s'hi adossaven (Vertamon, 1683, 40, \$75; Morera, 1899, 495; Sans, 1925).

Malgrat els precedents anteriors, en què queda clara la necessitat d'ampliar el recinte emmurallat, no és fins al final de 1368 quan trobem la primera referència concreta a la construcció del segon cercle mural o mur nou que envoltava el Corral. El 27 de desembre d'aquell any, el Consell va acordar la construcció del mur «del carrer losat», referint-se a l'antic vial romà situat davant la façana del circ. La resolució dictaminada pel Consell específica que el mur «sia fet davant aquell que ja és en lo dit carrer» del qual s'han de paredar «fenestre et foraviam». Aquest mur ja existent és, sens dubte, el de la façana del circ romà, amb la major part de les seves arcades paredades per 
reutilització de les voltes de substrucció de les grades del circ. Lògicament en aquest mur s'obririen portes i finestres que donaven a l'antic vial enllosat. ara un carrer dels ravals i d'entrada a la ciutat, tal com es descriu en la crònica de l'entrada solemne de la relíquia de santa Tecla (Sánchez, 1951). Les actes descriuen també les característiques que ha de tenir el nou mur assenyalant que «sia separat d'aquell e sia fet d'argamassa tot ab torres que isquen de fora e que aja X palms... gros e lo mur se puxa correr dins e de fora (Actes. 1984, 13). Igualment ordena que s'hi facin verdesques per defensar-lo.

Quatre dies després les obres s'han d'aturar perquè, segons les actes «no havem temps d'espatxar-lo per les companyies que sen fort prop» i per la manca dels materials constructius necessaris, "es a ssaber, calç, arena e pedra» (Actes, 1984, 15). Mentre la construcció del mur resta aturada, els treballs continuen amb l'excavació d'un vall davant la muralla, i la separació de la pedra per a la construcció del mur (Actes, 1984, 16). El 16 de gener de 1369 el Consell determinà de continuar les obres del mur nou i que algunes torres del mur vell fosssin reparades (Actes, 1984, 25-26). Les enormes despeses que comporten els treballs fan necessari, el 26 de gener, que l'arquebisbe ordeni als seus veguers d'obligar a pagar a tots aquells que no ho volien fer (Vertamon, $1683,41, n .27$ ). Per altra banda, en una reial ordre del 6 de març, el rei Pere III autoritza al Consell l'aplicació d'un impost sobre els aliments i altres mercaderies que entren a la ciutat (Sans, 1925, 122; Arnall, 1984, 113-114). En anys successius aquesta concessió s'anirà prorrogant per poder subvenir a les despeses originades pels treballs de fortificació de la ciutat (Sans, 1925, 123).

La muralla construïda en aquests treballs va consistir en l'erecció d'un llenç rectilini paral-lel a la façana de l'antic circ romà, formada per 50 arcs de $8 \mathrm{~m}$ d'altura i $300 \mathrm{~m}$ de longitud, que encara es troba dempeus en alguns sectors. Als extrems, la nova muralla presentava dues torres octogonals - la torre de les Monges a orient, $\mathrm{i}$ la torre de Miralcamp o Torre Grossa a occident-i, entre aquestes, la torre del Bordell a la part central i la torre de Framenors a la banda occidental del mur. En aquesta muralla s'obrien tres portes, conegudes amb els noms de portal de Framenors, del Bordell o Portalet i de les Menoretes o d'en Ses Mates. D'aquests, els dos primers estan clarament relacionats amb les torres del mateix nom, mentre que el darrer és encara de situació imprecisa, i pot correspondre a una porta situada entre el Portalet i la Torre de les Monges, adhuc a una porta situada al mur oriental, entre la dita torre i el castell del Rei (Palma, 1956, 37-38). De fet, la documentació gràfica que coneixem (vegeu més avall) només assenyala dues portes en aquest Mur Nou.

Fins al 1374 no disposem de cap més llibre municipal d'actes, raó per la qual desconeixem l'evolució dels treballs de construcció de les muralles després del seu endegament a les darreries del 1368. Tanmateix, el llibre de Vegueries dels anys 1371-1373 recull una notícia de les obres dels murs fetes entre els anys 1369 i 1370 en la qual s'especifiquen els pagaments realit- 
zats amb motiu de les obres efectuades en els portals del Bordell $i$ de Framenors, com també dels treballs fets en la torre de les Monges (Palma, 1956, 39). El 1374 les obres de construcció i reparació de les muralles encara continuaven, de manera que el Consell va determinar que els treballs fossin acabats ràpidament davant el perill que significava la penetració de tropes estrangeres pel nord del Principat (Actes, 1984, 69-70). No queda clar el moment en què els treballs de construcció del Mur Nou es donen per acabats. però a partir d'aquest any gairebé totes les notícies es refereixen a la conservació de les muralles o al seu esforç. Els treballs de manteniment de les construccions defensives són una pesada càrrega per al Consell municipal, que es veu obligat a destinar una bona part del seu pressupost a aquestes tasques. El 31 d'agost de 1375, el Consell determina que «lo mur del Corral e de la Ciutat sia reblert agual de la paret, per tal que l'aygua que hi cau haja escorredor» (Actes, 1984, 173; el subratllat és nostre). No obstant això, quatre anys després, davant l'estat ruïnós d'alguns panys de la muralla ustà peryllosament» dictamina que l'obra sigui «ivaçosament spatxada» (Actes, 1985,41).

Anys després, el 1383, una resolució consular assenyala que «lo mur de la ciutats és wen alguns lochs inderrocab», motiu pel qual hom determina de refer la muralla i construir una torre "en aquell hon los consols serà vist fahedon" (Actes, 1985, 82). En les actes de 1384 s'especifica que aquesta torre «començada per los cònsols passats» s'aixeca «vers lo castell del rei» (Actes, 1986, 24).

Malgrat totes aquestes notícies que ens descriuen diverses reparacions de la muralla - per altra banda cada vegada més escasses-, el seu manteniment és desatès pel Consell, que inverteix en d'altres afers. Davant d'aquesta situació, el 1385 el rei va pressionar els consols i prohoms perquè paguessin els treballs de fortificació de la ciutat (Sans, 1925, 124). Tot i les pressions reials, la conservació de la muralla continua essent descuidada. En una resolució de 1387, el Consell menciona la necessitat de reparar els murs de la ciutat, ja que es troben enderrocats en diversos llocs (Actes, 1987, 129). Tot $i$ això, les referències es redueixen a intervencions puntuals de manteniment o de sanejament, com en una resolució de 23 d'abril de 1393, en què el Consell determina que les torres de la muralla siguin pavimentades per evitar qualsevol accident (Actes, 1988,97). Aquestes reparacions no van afectar el disseny general del recinte emmurallat, el qual va romandre estable fins a les grans reformes implantades al segle XVI en aparèixer l'artilleria de setge. Aquesta evolució ha estat descrita en un altre treball (TED'A, en premsa).

\section{LES MURALLES MEDIEVALS SEGONS LA DOCUMENTACIÓ GRÀFICA HISTÖRICA}

Tot i que els documents gràfics que coneixem a hores d'ara són pocs, una mica tardans respecte a l'època que ens interessa i - de vegades- 
contradictoris, ens són imprescindibles per estudiar les muralles medievals tarragonines.

N'hem seleccionat cinc. En primer lloc, les dues vistes generals de la ciutat dibuixades pel pintor Anton Van den Wyngaerde l'any 1563, recentment publicades (Wyngaerde, 1986, 175-179). La més espectacular és, sens dubte, la panoramica de la ciutat agafada des d'un punt (del sector sudoccidental) immediat a la desapareguda església de Sant Fructuós (que existí en la zona on avui poden visitar-se les restes de la basílica del Forum de la Colònia). El dibuix «final» (no del tot acabat, tanmateix) permet veure les tres torres octogonals (la Grossa, la del Baluard i la de les Monges - aquesta darrera amb el nou baluard de Carles V incorporat-), però només una de les portes, la del Baluard o del Bordell (on actualment hi ha el carrer del Portalet), perquè l'altra està perspectivament «tapada» pel convent de Sant Francesc (o de Framenors, o dels Franciscans). A més a més, Wyngaerde situà una altra torre, de planta quadrangular, molt a prop de l'octogonal de la Torre Grossa i probablement al costat (o servint de portal) de la porta de Framenors, torre quadrangular (o portal) bastida ja en època moderna. Pel que fa al Mur Vell, la perspectiva utilitzada pel pintor flamenc - i la quantitat de construccions aleshores existents - fa difícil veure gaire cosa més que el castell o upalazio del Rey» i alguna altra torre, a més de dibuixar el llenç occidental del Corral, amb la porta dels Predicadors o del Roser (encara existent) (Fig. 3).

El segon dibuix de Wyngaerde presenta una vista de la ciutat des del SE (des del mar, a una certa distancia de la costa), centrada entre les restes de

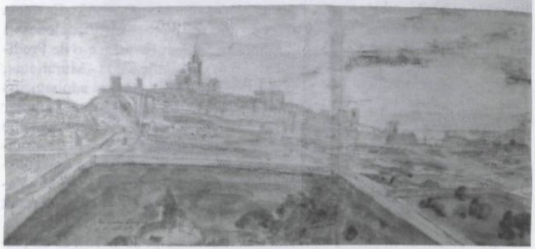

Fig, 3. Fragment de la vista de Tarragona dibuixada l'any 1563 per A. Van der Wyngaerde (Ashmolean Museum d'Oxford). 


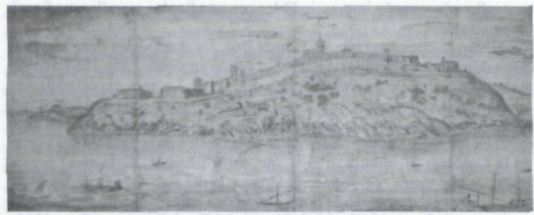

Fig. 4. Vista de la muntanya de Tarragona des del mar, segons A. Van den Wyngaerde (1563; Ashmolean Museum d'Oxford).

l'amfiteatre romà (tocant a la platja del Miracle) i la catedral (al cim de la muntanya). La distancia fa que els detalls quedin reduïts a simples taques, però es veuen força bé les construccions que conformen el castell del Rei. amb una porta al seu peu (SE), protegida també per una torre quadrangular (el «portal del Rein citat en la documentació medieval?). Més al sud. segueix el mur del Corral fins arribar a la torre de les Monges (davant del convent de Santa Clara), amb el baluard renaixentista adossat, però encara hi ha representada pel mig una altra torre quadrangular, la qual està situada aproximadament en el punt de gir de la muralla romana (en el desaparegut carrer de Sant Ermenegild) (Fig. 4).

De l'època de la guerra de Separació o dels Segadors, pels volts de 1641 , és un plànol que es limita a assenyalar les fortificacions existents fins aleshores i les que estaven projectades amb motiu de la nova situacio militar (Negueruela, 1985, 60-72; Gabriel/Hernández, 1985, 59-63). Es tracta d'una «Planta de la ciudad de Tarragona con sus nuebas fortificaciones» $\mathrm{i}$ alguns edificis immediats, com el monestir de Sant Domènec o de Predicadors. En el sector que ens interessa, només està indicada la "Muralleta", a més del «Castillo que llaman de el Rey", força afectat pels adobaments $\mathrm{i}$ les reformes. Hi ha assenyalades la Torre Grossa, la torre quadrangular pròxima (probablement protectora del portal de Framenors), una mena de ziga-zaga entre aquesta última i la torre del Baluard (que, com la quadrangular de davant del convent de Sant Francesc, sembla més aviat una construcció feta dins mateix de la muralla); entre la torre del Baluard i el «Valuarte que llaman del Rey» hi ha «la puerta de la marina», l'actual Portalet (Fig. 5).

De l'època de la guerra de Successió (del principi de 1716), és un plànol francès, sense títol, de la part alta de la ciutat, aquesta vegada amb indicació de l'estructura urbana interior (Negueruela, 1985, 72-75). Tot i 


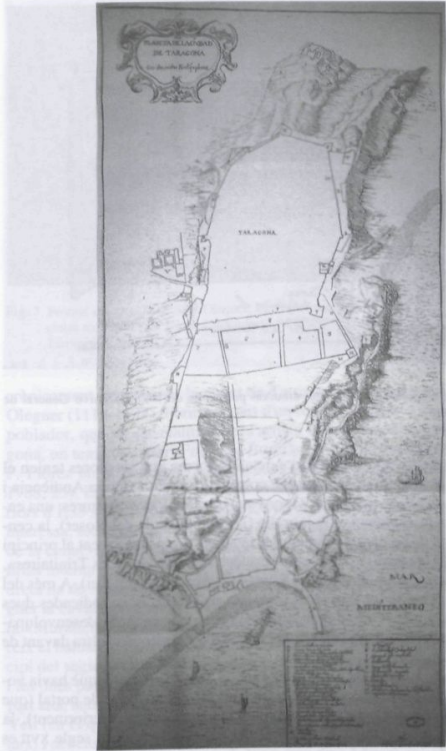

Fig. 5. NPlanta de la ciudad de Tarragona con sus nuebas fortifiçaçiones» (sic), dibuixada pels volts de 1641 (Archivo General de Simancas). 


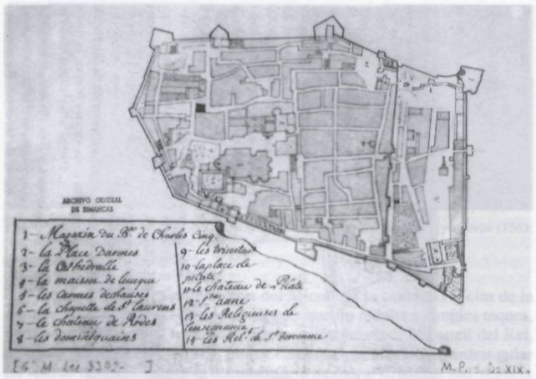

Fig. 6. Planol francès de Tarragona, dibuixat pels volts de 1716 (Archivo General de Simancas).

l'escala, la planta indica amb força detall la forma que aleshores tenien el Mur Nou i la Muralleta. El mur que corre entre l'actual antiga Audiència i «le chateau de Pilate» presenta, segons aquest plànol, tres obertures: una entre l'esmentada Audiència i la muralla (l'actual baixada del Roser), la central del portal de n'Olivera (l'arc que el tancava va ser enderrocat al principi del segle XIX) i la porta existent sota l'església de Natzaret $i$ «les Trinitaires», que comunicava amb «la place de Pilate» (l'actual plaça del Rei). A més del Castell del Rei i de les torres del portal de n'Olivera, hi ha indicades dues torres quadrangulars més, molt amples, com una mena de desenvolupament de la muralla, una a l'alçada del carrer d'en Mediona i l'altra davant de la plaça del Pallol.

Quant a la Muralleta, no és dibuixada la Torre Grossa perquè havia volat l'any 1700, però sí la porta de Framenors, amb una mena de portal (que podria correspondre a la torre quadrangular esmentada anteriorment), la ziga-zaga de la muralla, la torre del Baluard i la porta que al segle xyu es deia de la Marina (també amb una mena de portal, molt més gran que el de Framenors) (Fig. 6).

Finalment i ja de la segona meitat del segle XvII (pels volts de 1776: vegeu Capdevila, 1935, 40, nota 14), és el baix relleu que intenta, ana- 


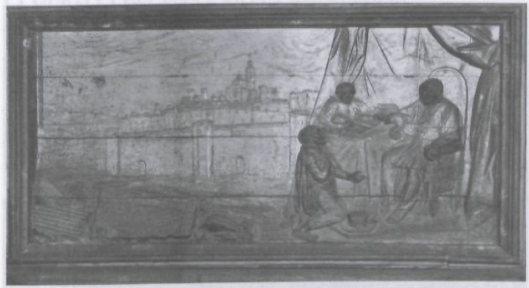

Fig. 7. Frontal del retaule de Sant Oleguer, de Francese Bonifas, amb la representació de la ciutat medieval i de l'acte d'infeudació de l'any 1129 (retaule de 1776: Catedral de Tarragona).

crònicament, representar la ciutat de Tarragona en l'època de l'arquebisbe Oleguer (1118-1137). Formava part d'un retaule, dedicat a l'arquebisbe repoblador, que va ser realitzat per l'artista vallenc (però establert a Tarragona, on tenia un taller) Francesc Bonifas, que ja havia col-laborat amb el P. Flórez en la part gràfica del volum XxIV de l'España Sagrada (Circ, 1988,25 ). Es tracta d'una peça, de fusta daurada (amb unes mesures interiors d'1,35 x 0,63 m), en la qual l'artista separa dues escenes o temes. Ens interessa, sobretot, la part que és a l'esquerra de l'espectador, amb una visió de la ciutat (en un relleu molt baix) des de la Rambla Vella. Tot i que Bonifas intenta reconstruir l'aspecte de la ciutat en el segle XII (l'escena de la dreta ha de relacionar-se amb l'acte d'infeudació fet per l'arquebisbe Oleguer al cavaller normand Robert, l'any 1129) (Fig. 7), ja hi és representada la «Muralleta», bastida dos segles després (però, per exemple, no hi apareix el baluard de Carles V, que no començaria a desmuntar-se fins al principi del segle XIX). S'hi distingeixen perfectament les tres torres octogonals $i$ les dues portes, amb matacans de defensa inclosos, del mur inferior; en la part alta, entre altres edificis, són representats clarament per damunt del Mur Vell (en el qual s'observen almenys quatre torres, aparentment quadrangulars) i del castell del Rei, la torre del Paborde, la Catedral i el castell del Patriarca (Fig. 8). És interessant confrontar aquesta vista anacrònica amb el aPlan de la ciudad de Tarragonas, dibuixat abans de 1769 per Antonio Alcedo i publicat en el volum de l'España Sagrada en què col-laborà Bonifas (Flórez, 1769, 80) (Fig. 9). 


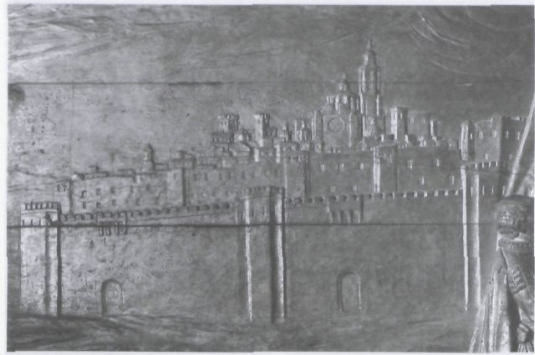

Fig. 8. Detall del frontal de la Fig. 7. En primer terme, la Muralleta del s. XIV (Catedral de Tarragona).

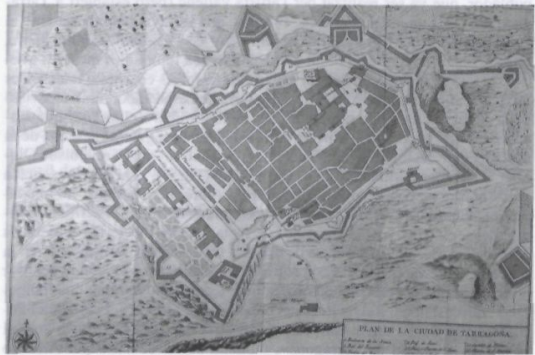

Fig. 9. «Plan de la ciudad de Tarragona» dibuixat per A. Alcedo per a l'España Sagrado del P. Flórez (1769) 


\section{LA MURALLA DEL SEGLE XII I LA INTERVENCIÓ ARQUEOLÖGICA EN EL NÚMERO 20 DEL CARRER DELS FERRERS}

El portal de n'Olivera, protegit per dues torres - tradicionalment conegudes com d'Arandes i del Baró de les Quatre Torres-, ja no existeix. No obstant aixó, les dues torres es troben fossilitzades en les cases adjacents del carrer dels Ferrers i del carrer de l'Enrajolat. Una petita plaça exterior i el traçat axial del carrer Major en direcció a la façana gòtica de la catedral, permeten imaginar amb claredat l'ordenació urbana de la ciutat medieval.

Uns treballs de remodelació efectuats en l'immoble situat en número 20 del carrer dels Ferrers, tot just al costat de la torre d'Arandes, va possibilitar que el TED'A realitzés una intervenció arqueològica entre els mesos de juliol i de febrer de 1989. En els baixos d'aquesta casa va aparèixer un impressionant enllosat de pedra calcària local. Les dimensions de les lloses i l'existència, a sota, de diverses voltes del circ romà, van justificar un estudi aprofundit d'aquest sector. D'aquesta forma, les tasques d'excavació — adaptades als condicionants estructurals i a les obres de reforma- es perllogaren durant alguns mesos $i$, a la seva fi, van permetre demostrar amb claredat l'evolució arquitectònica del sector des del segle I dC fins als nostres dies.

En època dels emperadors flavis es va construir en la part superior de Tàrraco un monumental complex arquitectonic per a cerimònies, un forum provincial en el qual anualment es reunia l'assemblea de notables de la provincia Hispania Tarraconensis o citerior. El conjunt estava format per un recinte sagrat situat en la part més alta (entorn del gran temple de culte imperial); una enorme plaça, de $300 \times 150 \mathrm{~m}$, als seus peus i voltada de pòrtics de dos pisos, i, com a edifici annex, un circ situat en posició transversal. La construcció del circ - la darrera en materialitzar-se - va aprofitar l'existència del mur en terrassa i de contenció de la gran plaça. Es tracta d'un mur de $300 \mathrm{~m}$ de longitud, amb unes fonamentacions de $6 \mathrm{~m}$ d'altura. A aquest mur s'adossaren les voltes que sostenien les grades septentrionals del circ. En la part central, tot coincidint amb l'eix de simetria de les dues places del forum provincial, es coneixien, des de temps antic, dues voltes d'una mida més gran $\mathrm{i}$ amb murs gruixuts que es diferenciaven de la resta de les voltes perquè travessaven la fonamentació del mur esmentat abans i penetraven a l'interior de la plaça. Aquestes voltes estan ocupades actualment per dos locals nocturns, i n'hi ha una que es troba situada precisament sota el solar on es va efectuar la intervenció del TED'A. Aquestes voltes formaven en realitat part d'un accés monumental, el qual conduïa des de l'arena fins a una tribuna o escalinata situada en la part central de la graderia del circ (Circ, 1988, 73-74).

L'accés constava d'una escala en forma d'hemicicle, un gran enllosat pla i una escala que baixava fins a la pista. Per aquest trajecte hi anava la gran processó inaugural o pompa circensis que lligava els rites religiosos de 


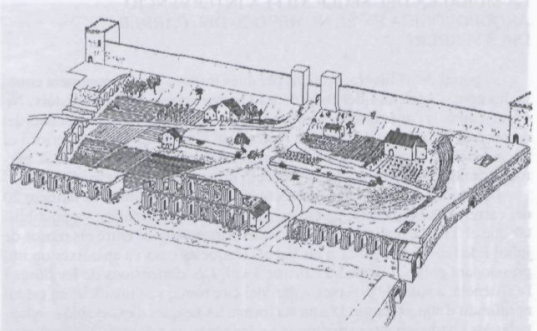

Fig. 10. Reconstrueció hipotètica del sector del Corral, pels volts de l'any 1200 (TED'A).

caire polític amb la participació popular, amuntegats a les grades tot esperant l'inici dels espectacles.

La part superior de l'escala, en forma d'hemicicle, estava limitada per dos murs de carreus coronats amb motllures i recolzava damunt de quatre voltes, les dues esmentades anteriorment $\mathrm{i}$ dues de més petites als costats.

En el segle XII aquest accés monumental es trobava encara dempeus, cobert en part pels estrats formats en el període d'abandonament. Probablement, es trobava ja sense les pintures, les plaques i la decoració estatuària original, pero conservava encara el seu caràcter monumental. Per altra banda, es tracta de l'únic punt per on es podia superar amb comoditat el desnivell - de gairebé dotze metres- existent entre la pista del circ i la gran plaça superior. En fortificar el mur en terrassa del forum s'assegurava, en realitat, la part superior d'aquest pendent, i es transformava tota la graderia septentrional del circ en un talús, més o menys enrunat, amb les seves voltes subterrànies transformades en magatzems i amagatalls (Fig. 10).

Per a la construcció del portal de n'Olivera es va tancar amb un nou mur l'espai de la gran escala romana seguint l'alineació del mur en terrassa del forum provincial, i aixecant dues torres avançades en els seus extrems. La porta es va situar adossada a la torre oriental - la qual cosa, sens dubte, determinà l'alineació del carrer Major-, mentre que el mur de tancament intermedi correspon a les façanes dels números 20 i 22 del carrer dels Ferrers. En la intervenció efectuada pel TED'A en el número 20 es van poder 
documentar, a més a més, la secció d'aquest mur i la seva superposició a les estructures romanes.

En una intervenció realitzada l'any 1986 per X. Dupré i J.A. Remolà, en l'angle format per la torre d'Arandes i per la façana del número 20 del carrer dels Ferrers, es van localitzar les restes de l'enllosat romà esmentat i es va poder observar com la part inferior de la torre (feta amb grans carreus mans reaprofitats) recolza directament sobre les estructures romanes. Malgrat la manca de dades estratigràfiques, el fet que aquest sector de la torre estigui construit amb la mateixa tècnica que el mur identificat pel TED'A - atribuit al segle XII-, permet pensar que la base de la torre d'Arandes sigui l'original.

La muralla del segle XII va ser constrü̈da directament damunt de la pavimentació romana, realitzada amb grans lloses i sustentada sobre un sistema de voltes inferior. La muralla recolzava lateralment en el mur de tancament occidental de la gran escalinata, mentre que les torres se sustentaven sobre la plataforma superior del circ. La muralla es va construir amb carreus romans reaprofitats, i va formar dos llenços paral-lels amb un reble interior de terra i pedres irregulars. Els carreus es van lligar amb argamassa fent servir petits codols en les juntures.

Posteriorment, un cop la muralla va ser amortitzada amb l'ampliació del recinte urbà en el segle XIV, les cases que hi eren adossades van anar desmuntat lentament el parament interior (el qual només va restar conservat en alguns punts) al mateix temps que el llenç exterior esdevenia la façana de les cases $i$ s'hi obrien portes i finestres, com també succeïa en les torres laterals (Fig. 11).

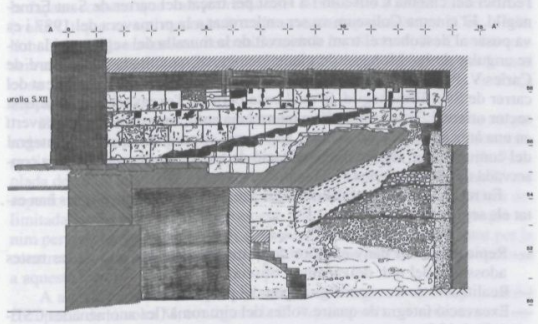

Fig. 11. Secció general de la intervenció en el núm. 20 del carrer dels Ferrers (TED'A). 


\section{LA MURALLA DEL SEGLE XIV I ELS TREBALLS ARQUEOLÒGICS EN LA CAPÇALERA DEL CIRC ROMÀ}

Des de la meitat dels anys vuitanta, una de les tasques arqueologiques encetades per l'Ajuntament de Tarragona i la Generalitat de Catalunya és la recuperació de la capçalera del circ romà, situada entre els carrers de Sant Ermenegild i de Sant Oleguer i la Rambla Vella. La primera fase d'aquesta investigació va culminar amb la publicació dels treballs d'excavació i de documentació realitzats pel Servei d'Arqueologia entre els anys 1984 i 1986 (Circ, 1988). El 1986, la creació del Taller Escola d'Arqueologia per part de l'Ajuntament de Tarragona, l'INEM i el Fons Social Europeu va permetre la continuació d'aquests treballs al mateix moment que, de forma paral-lela, s'encarregava el projecte de restauració del conjunt a l'arquitecte Andrea Bruno i es portaven a terme les expropiacions oportunes.

La capçalera del circ està delimitada per la muralla tardorepublicana que tancava per aquest costat la ciutat romana. El seu traçat va condicionar totes les fortificacions posteriors, amb el resultat d'un ampli conjunt de reparacions, refaccions, construccions de nous llenços, portes i elements defensius que resumeixen la història de Tarragona com a plaça forta des del segle II $\mathrm{aC}$ fins a mitjan segle xIx. Per la banda meridional, com ja hem dit més amunt, la façana del circ va ser reaprofitada en el segle XIV per a la construcció de la «muralleta».

L'any 1987 totes aquestes construccions restaven amagades al sud per l'edifici del cinema Coliseum i a l'oest pel traçat del carrer de Sant Ermenegild. El cinema Coliseum va ser enderrocat a la primavera del 1987 i es va posar al descobert el tram conservat de la muralla del segle XIv i la torre angular de les Monges, de planta octogonal, envoltada pel baluard de Carles V. Posteriorment, 1'hivern de 1988, es va aixecar tot el paviment del carrer de Sant Ermenegild, la qual cosa permeté l'excavació de tot aquesı sector oriental. Tota la superfície intermèdia entre aquests límits es convertí en una àrea arqueològica visitable alhora que es produīa l'excavació integral del conjunt i, per tant, la documentació de tota la seqüéncia històrica conservada des del segle II aC fins ara.

En relació amb la muralla del segle XIV, els treballs arqueològics han estat els següents:

- Repicament del pany exterior de la muralla i eliminació de les restes adossades del mur del cinema Coliseum.

- Realització de tres sondeigs al peu del pany exterior.

- Excavació íntegra de quatre voltes del circ romà (les anomenades CSEJ, K, L i M).

- Excavació d'una part del farciment interior de la Muralleta. 


\section{LA SEQÜÈNCIA D'ÈPOCA MEDIEVAL}

Ja hem vist anteriorment com entre els segles XII i XIV, les restes del circ constituïen un espai extramurs ocupat per construccions de diversa índole i denominat explícitament en la documentació de l'època «el Corral». Una sèrie d'evidències arqueològiques testimonien aquesta fase de construccions "suburbanes» anteriors a la construcció de la muralla del segle XIV.

La intervenció més espectacular correspon al buidatge del reompliment interior de la muralla romana situat tot just al costat de la porta d'accés a la ciutat en època romana i a la seva transformació en un espai construït proveît d'un arc monumental apuntat de les mateixes dimensions que els ares romans de la façana del circ amb els quals es troba alineat. Per fer possible aquesta obra es va buidar tot el reble interior de la muralla romana, de 3,5 m d'amplada i $7 \mathrm{~m}$ d'altura, ocupat per capes superposades de toves damunt d'una base de pedres lligades amb morter de calç. També es van desmuntar tots els carreus del pany interior i es va restar com a paret el mur adossat del circ romà realizat en opus caementicium (Circ, 1988, fig. 49). Aquest espai va ser excavat als anys setanta per P. M. Berges sense que se n'hagin publicat els resultats estratigràfics obtinguts. En realitat, aquesta construcció és una prova que en el període comprès entre els segles XII i XIV, les voltes de l'angle sud-oriental del circ van ser reaprofitades per formar part d'una edificació de característiques importants. Aquest edifici presentava una façana formada, en primer lloc, pel nou arc apuntat que limitava l'espai guanyat a la muralla, seguit, probablement, pels dos arcs de la façana romana que van ser restaurats (voltes A i B) i per un tercer arc (volta C) que va ser reconstruit en la seva meitat occidental (Circ, 1988, làm. II, a). Malauradament, l'estratificació de les voltes A, B i C no ha conservat restes d'aquesta ocupació medieval anterior al segle xIv, per la qual cosa la datació en aquesta època de la restauració dels ares es força hipotètica.

En un segon moment, l'arc apuntat adossat a la façana romana va ser paredat amb un mur d'opus spicatum que presenta dos cossos diferenciats, realitzats en dos moments successius. L'inferior pareda la meitat de l'amplada de l'arc i conserva un brancal d'una porta bastida amb carreus. El cos superior inutilitza aquesta mateixa porta $i$ hi situa damunt una espitllera delimitada també per carreus. Novament, l'únic argument cronològic que tenim per datar aquesta refacció és el terminus ante quem subministrat per la construccí de la Muralleta a partir de 1368, ja que la torre angular s'adossa a aquesta façana i l'amorteix.

A aquest moment anterior a la muralla del segle xIV correspon també l'ocupació de la volta $\mathrm{M}$, contigua a la $\mathrm{C}$. Aquesta volta, ja sense la seva coberta d'època romana, va ser reacondicionada amb una estructura de dues plantes recolzada en els murs romans $i$ amb dos arcs diafragmàtics apuntats 


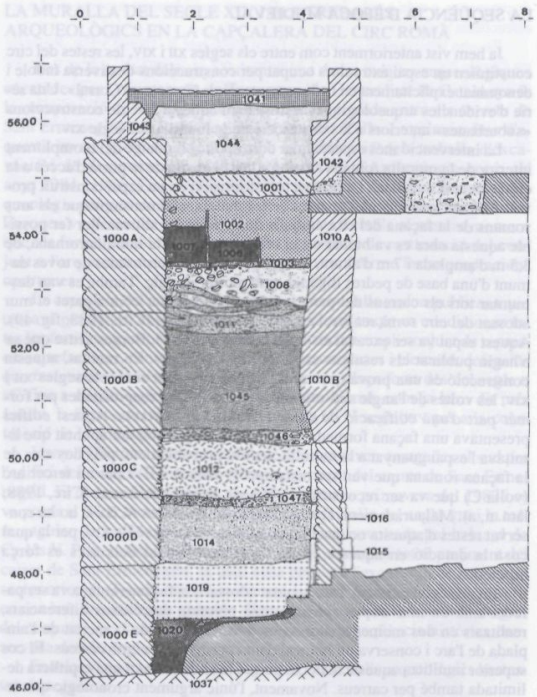

Fig. 12. Secció estratigrafica de l'excavació del farciment de la muralla medieval del s. xav, bastida aprofitant $\mathrm{Y}$ antiga façana del cire romà (TED'A).

de nova construcció. Aquest àmbit presentava una porta que va restar inutilitzada més tard per la construcció de la Muralleta, la qual cosa prova la seva anterioritat. Malgrat tot, aquest àmbit es va enderrocar al segle següent, 
i va deixar damunt del paviment d'utilització un ric conjunt de ceràmiques del principi del segle XV, eines de ferro i un tresoret de monedes de plata de Jaume II, juntament amb les dovelles dels ares i de les restes del pis superior que han pogut ser recuperades en les excavacions realitzades.

\section{LA CONSTRUCCIÓ DE LA MURALLA DEL SEGLE XIV}

Si la documentació escrita ens situa amb precisió els inicis de la construcció de la Muralleta l'hivern de 1368-1369, I'arqueologia ha permès documentar el sistema constructiu emprat. Davant de la façana del circ, a $2,70 \mathrm{~m}$ de distància, es va començar a aixecar un nou mur d'1,50 m d'amplada. El mur està bastit amb pedres irregulars, de grandària mitjana, agafades amb argamassa, i fonamentat directament sobre la roca que talla els nivells del carrer d'època romana (Fig. 12). Aquest mur presenta una sèrie de cossos superposats ( $1000 \mathrm{a}, \mathrm{b}, \mathrm{c}, \mathrm{d}$ i e), els quals coincideixen amb el paredat dels arcs de la façana del circ $i$ amb els estrats que configuren el reble interior. La muralla, així, es va edificar construint al mateix temps els murs exterior i interior i es va omplir l'espai intern amb pedres i terra. D'aquesta forma, es van fer talussos que van permetre aixecar-la en la seva totalitat, fins a una altura de gairebé $10 \mathrm{~m}$, sense necessitat de recórrer a l'ús de bastides. Entre alguns dels diferents cossos del farciment apareix un nivell de composició diferent format durant els treballs de construcció dels murs del cos superior, amb el desbast de la pedra i la fabricació del morter. Quan el mur era prou alt, es reomplia l'espai interior fins a cobrir la seva alçada, es començava un altre tram, i així es donava lloc a la formació d'un altre nivell de treball. A l'interior de la muralla es van situar, a una certa distància, uns murs perpendiculars que actuaven com a tirants. Un d'aquests murs va aparèixer en l'excavació realitzada davant de la volta $\mathrm{C}$.

L'estratigrafia efectuada en aquest punt ha permès documentar en la part superior de la muralla les restes d'un paviment de rajols i els seus nivells preparatoris que daten d'època contemporània. Més avall, a la mateixa alçada que la part superior del circ, apareix un paviment anterior. Està realitzat a base de pedres irregulars travades amb morter i cobreix el primer nivell del farciment $\mathrm{i}$ una part del caementicium del circ.

Els primers nivells del farciment $(1001,1002,1003)$ contenen materials d'època moderna i, juntament amb la pavimentació anterior, han de ser relacionats amb la reconstrucció del parament intern de la muralla situat davant les voltes M, L i K. Sota aquests nivells es conserven les restes que coronaven la part superior del farciment original de la muralla del segle XIV, desaparegudes en part amb l'enderroc del llenç intern. Aquestes restes segueixen la mateixa tècnica constructiva que en el segon cos del mur que 
tapia la volta C. Estan constituïdes per dos murets de tapial d'uns $50 \mathrm{~cm}$ d'amplada, els quals es disposen de forma paral-lela als paraments de la muralla. El primer (1007) presenta una cara adossada al llenç exterior i l'altra arrebossada amb una espessa capa d'argamassa. Per altra banda, el segon (1006) s'adossa a l'arrebossat del primer, mentre que l'altra cara apareix igualment arrebossada.

Sota aquesta estructura segueix la resta del farciment de la muralla. Tot i que es tracta d'un cos homogeni, hi hem distingit diferents nivells segons la coloració que presentaven $(1008,1011,1045,1012,1014,1019)$. Cada un coincideix amb els diferents trams horitzontals que conformen el parament exterior $i$ el tiram 1005. Entre alguns d'aquests nivells són visibles petits estrats $(1046,1047)$, no superiors als trenta centímetres de potència, de diferent composició i textura. Mentre els primers són formats a base de terra els altres es componen principalment de petites pedres i fragments d'argamassa.

En els nivells inferiors del farciment s'aprecia clarament la rasa de fonamentació del llenç exterior (1027) i el seu reompliment (1028), com també els nivells romans extrets amb l'excavació de la rasa i abocats al costat (1024, 1022). Finalment només cal assenyalar la presència d'alguns nivells d'època romana pertanyents al farciment constructiu del circ (1028, $1034 \mathrm{i}$ 1033) i a una petita claveguera paral-lela a la façana (1025).

Un altre tall estratigràfic es va realitzar a $10 \mathrm{~m}$ de distància, davant de la volta L. En aquest punt, l'estratigrafia va demostrar que el mur interior que pareda les voltes $\mathrm{K}$, L i M correspon, en realitat, a una refacció posterior, del segle XVII o XVII, la qual talla clarament el reble interior de la muralla del segle xIv, únicament conservat en la seva part inferior. D'altra banda, els sondeigs efectuats al peu del mur exterior de la muralla van resultar totalments infructuosos perquè la construcció del cinema Coliseum - $\mathrm{i}$, anteriorment, la del parc d'Artilleria - va comportar el rebaix de la roca amb eliminació de qualsevol vestigi d'ocupacions anteriors.

A l'extrem de la muralla es va bastir una torre octogonal amb paraments de pedres irregulars agafades amb morter de calç $i$ amb els angles de carreus de mida petita. L'interior de la torre presenta un reompliment de terra i pedres que formen un cos compacte el qual limita en la seva part superior amb una cambra coberta per una cúpula. Una porta comunicava aquesta cambra amb el passeig de ronda de la muralla i n'assenyala avui la situació, ja que ha desaparegut en la seva totalitat arrasat per les construccions posteriors. Com hem dit abans, la torre era gairebé bessona de la Torre Grossa, situada a l'altre extrem de la muralla, i d'una tercera situada a la part mitjana del pany, protegint el portal del Baluard. La magnífica vista de Tarragona (citada més amunt) dibuixada per A. Van den Wyngaerde il.lustra l'aspecte d'aquesta muralla en el segle XVI. La generalització en aquesta època de l'artilleria de setge va provocar l'aixecament entorn de la torre d'un 


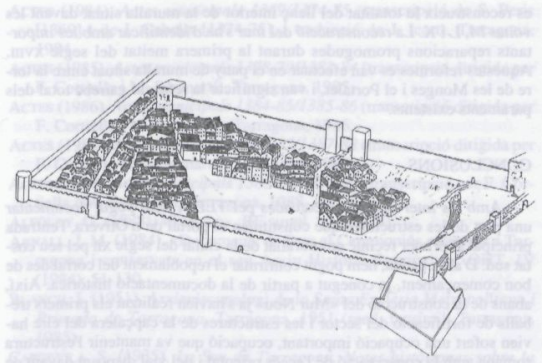

Fig. 13. Reconstrucció hipotetica del sector del Corral, a mitjan segle XIY (TED'A).

baluard en punta de sageta que protegia l'angle de la muralla. Les restes d'aquest baluard, visible també en el dibuix de Wyngaerde, han estat documentades entorn de la torre amb uns murs exteriors de carreus $i$ un reble interior de morter de calç, sorra i pedres.

La torre de les Monges, també coneguda com a torre de Carles V, ha estat tradicionalment datada en el segle Xvı ( $v$. Circ, 1988, 68). Els treballs d'excavació i d'anàlisi de les estructures arquitectòniques ens ha permès comprovar que la construcció de la torre i la de la muralla són contemporànies; en conseqüència, doncs, la torre octogonal és del segle XIV $\mathrm{i}$ ha de ser la «torra de les monges» dels documents medievals. Aquesta hipòtesi es veu avalada per la tipologia de la mateixa torre, que és típica d'aquell moment tardo-medieval, ja que si hagués estat bastida en el segle XVı hauria estat arcaîtzant i gairebé inútil per a la defensa de la ciutat enfront d'un exèrcit dotat de la desenvolupada artilleria de l'època moderna.

La construcció, al segle XVI, del baluard de Carles V-que folra la meitat inferior de la torre- fou la causa que portà a l'error d'identificació i, consegüentment, de datació (Fig. 13).

Finalment, hem de destacar el fet que tant els paraments com el farciment originals no presenten cap evidència d'haver sofert reparacions o canvis en la seva estructura fins ben entrada l'època moderna, moment en què 
es reconstrueix la totalitat del llenç interior de la muralla situat davant les voltes $\mathrm{M}, \mathrm{L}$ i K. La reconstrucció del mur s'ha d'identificar amb les importants reparacions promogudes durant la primera meitat del segle XVIII. Aquestes reformes es van efectuar en el pany de muralla situat entre la torre de les Monges i el Portalet, i van significar la refacció gairebé total dels paraments existents.

\section{CONCLUSIONS}

Amb les intervencions efectuades pel TED'A hem pogut documentar una part de les estructures que constituïen el portal de n'Olivera, l'entrada principal al primer recinte emmurallat de la ciutat del segle XII pel seu costat sud. D'altra banda, hem pogut confirmar el repoblament del corral des de bon començament, ja conegut a partir de la documentació històrica. Així, abans de la construcció del $«$ Mur Nou» ja s'havien realitzat els primers treballs de fortificació del sector i les estructures de la capçalera del circ havien sofert una ocupació important, ocupació que va mantenir l'estructura romana amb la conservació de l'accés oriental i del vial disposat davant de la façana del circ. El reaprofitament de les voltes va provocar el paredat dels arcs de la façana i l'obertura de portes i finestres, que donaven al carrer Enllosat.

La muralla del segle xIV va significar la definitiva transformació del sector, amb la construcció de la torre de les Monges en el lloc on havia estat l'antiga porta romana (Circ, 1988, 45-47) i l'aprofitament del carrer enllosat en tota l'extensió del parament exterior. La seva construcció va provocar l'aparedament dels arcs de la façana del circ, i l'accés a les voltes del circ per l'exterior oposat d'aquestes, és a dir, des del podi del circ, per a la qual cosa fou necessària l'obertura de portes en l'esmentat mur romà.

Ja al segle Xvm es realitzen els darrers treballs de reparació del «Mur Nous, abans del seu enderroc definitiu, decretat l'any 1789. L'enderroc es va produir a causa de la insalubritat dels edificis adossats al mur i a la dificultat de construir-ne de nous. L'interès militar del seu extrem meridional - amb la torre de les monges i el baluard de Carles V, construitt entorn de la seva base - va evitar la seva destrucció; en va continuar l'ús militar, com a magatzem o parc d'Artilleria, fins ben entrat el nostre segle, en què passà a propietat municipal.

\section{BIBLIOGRAFIA}

ACTES (1983), Actes municipals 1358-1360 (transcripció de S. Peris i traduccio de J. Icart), Tarragona, 1983. 
Actes (1984), Actes municipals 1369/1374-75 (transcripció de S. Peris [1369] i de J. Cubells [1374-75], i traducció de J. Icart), Tarragona, 1984.

ACTES (1985), Actes municipals 1378-79/1383-84 (transcripció dirigida per F. Cortiella i M. Sanmartí), Tarragona, 1985.

ACTES (1986), Actes municipals 1384-85/1385-86 (transcripció dirigida per F. Cortiella i M. Sanmartí), Tarragona, 1986.

ACTES (1987), Actes municipals 1386-87/1387-88 (transcripció dirigida per F. Cortiella i M. Sanmartí), Tarragona, 1987.

ACres (1988), Actes municipals 1388-89/1393-95 (transcripció per F. Cortiella i M. Sanmartí), Tarragona, 1988.

ALFOL.DY, G. (1978), «Tarraco», RE suppl. xIV (1978).

ARNALL, J. M. (1984), «Documents de Pere el Ceremoniós referents a Tarragona i conservats en el seu Arxiu Històric Provincial», QHT, IV (1984), 51-130.

Blanch, J. (1951), Arxiepiscopologi de la Santa Església Metropolitana i Primada de Tarragona, Tarragona, 1951 (reed. facsímil, Tarragona, 1985).

CAPDEVILA, S. (1935), La Seu de Tarragona. Notes històriques sobre la construcció, el tresor, els artistes, els capitulars, Barcelona, 1935.

Circ (1988), X. Dupré, J. Masso, M.L. Palanques i P. Verduchi, El Circ romà de Tarragona, I. Les Voltes de Sant Ermenegild, Barcelona, 1988.

Flórez H. (1769), España Sagrada, tom XXIV, Madrid, 1769.

GABRIEL R. i HeRnÁNDEZ, E. (1985), «Proyecto de fortificación de Tarragona en 1641», BA, èp. v, núm. 3 (1985), 59-63 i un plànol plegat.

MORERA, E. (1899), Tarragona Cristiana, vol. II, Tarragona 1899 (-1901); reed. de 1954 (2a. reed.: 1982).

NegueRUel A, I. (1985), «Dos importantes planos de Tarragona en el Archivo de Simancas», QHT, V (1985), 59-75.

Palma (1956), A. de Palma de Mallorca, Las calles antiguas de Tarragona (siglos XIII-XIX) (text en català), tom I, Tarragona, 1956.

RECASENS, J.M. (1975), La ciutat de Tarragona, Barcelona, 1975.

SÁnCHEZ ReAl, J. (1951), El brazo de Santa Tecla, Tarragona, 1951.

SANS, J. (1925), «Memoria presentada por D. Fernando Camino, coronel del cuerpo de ingenieros de ejército, como resultado de sus investigaciones en el Archivo General de la Corona de Aragón”, BA, època II, núm. 28 (1925), 121-125.

SERRA VILARÓ, J. (1935), «Excavaciones en la Necrópolis romano-cristiana de Tarragona», MJSEA, núm. 133, Madrid, 1935.

TeD'A (Taller Escola d'Arqueologia), (1987), «Els enteraments del Parc de la Ciutat i la problemàtica funerària de Tàrracon, Memòries d'Excavació, núm. 1. Tarragona, 1987.

(1989), «Un abocador del segle v dC en el Fòrum Provincial de Tàrraco», 
Memòries d'excavació, núm. 2, Tarragona, 1989.

«Una aproximació a les fortificacions modernes i contemporànies de Tarragona», QHT (en premsa).

VALLS TABERNER, F. (1926), «Documents de Sant Olegued, a BA, època II, núm. 30 (1926), 161-164.

VERTAMON (1683), Anònim (F. Vertamon), Apología histórica legal por la Invictíssima Protomártir Santa Tecla, su Santa, y Metropolitana Iglesia de Tarragona, Primada de las Españas, y el Ilustrissimo, y Reverendissimo Señor Don losef Sanchiz. Arçobispo della, sobre la Iurisdicción omnímoda, civil y criminal, y mixto imperio, que tiene en aquella Ciudad, por indiviso, con su Magestad... (sense lloc ni data d'impressió, probablement: Barcelona 1684), edició facsímil, Tarragona, 1984.

VILLANUeVA, J. (1851), Viage literario á las iglesias de España, tom XIX, Madrid 1851.

VIRGILI, A. (1984), «La qüestió de Tarraqüna abans de la conquesta catalanan, QHT, IV (1984), 7-36.

WyngafRDE (1986), Ciudades del Siglo de Oro. Las Vistas Españolas de Anton Van den Wyngaerde (edició dirigida per R.L. Kagan), Madrid, 1986.

\section{SIGLES}

BA: Butlletí Arqueològic/Boletín Arqueológico (Tarragona).

MJSEA: Memorias de la Junta Superior de Excavaciones y Antiguledades (Madrid)

QHT: Quaderns d'Història Tarraconense (Tarragona)

RE: Real Encyklopädie der Klas. Altertums

TED'A: Taller Escola d'Arqueologia 